\title{
Resilience, Regime Shifts, and Guided Transition under Climate Change: Examining the Practical Difficulties of Managing Continually Changing Systems
}

\author{
${\text { Brenda B. } \text { Lin }^{I}}^{\text {and Brian Petersen }}{ }^{2}$
}

\begin{abstract}
Managing terrestrial systems has become increasingly difficult under climate change as unidirectional shifts in climate conditions challenge the resilience of ecosystems to maintain their compositional structure and function. Despite the increased attention of resilience management to guide transformational change, questions remain as to how to apply resilience to manage transitions. Rather than pushing systems across thresholds into alternative states, climate change may create a stepwise progression of unknown transitional states that track changing climate conditions. Because of this uncertainty, we must find ways to guide transitioning systems across climate boundaries towards states that are socially and environmentally desirable. We propose to ease the uncertainty of managing shifting systems by providing an approach to adaptive management that we call guided transition, where socially and environmentally important ecosystem functions are preserved through transitions by considering and maintaining the species and structures needed for the desired functions. Scientifically, it will require a better understanding of the relationships between structure, species composition, and function for specific systems. Managers will also need to identify important functions at the local, regional, and national scale, and to determine how best to transition systems to a desired state based on existing scientific knowledge. Guided transition, therefore, helps guide the process of adaptive management by specifying a function-based management pathway that guides transitions through climatic changes.
\end{abstract}

Key Words: ecosystem function; ecosystem structure; resilience management; species composition; unidirectional shifts

\section{INTRODUCTION}

Over the past three decades, resilience has emerged as an important framework for analyzing the sustainability of socialecological systems (Folke 2006, Gallopín 2006, Walker and Salt 2006). Resilience is considered as the ability of a complex system to continue to perform its desired functions when it comes under stress or external shock (Folke 2006). It is an important concept that can be applied to socioeconomic and environmental systems that face changing circumstances whether they are the product of less noticeable, slow moving changes, such as global warming, or sudden and unexpected shocks, such as extreme climate events. Resilience thinking increases the awareness of complex systems, their various interacting parts, and their ability to cope with changes without having to predict with great accuracy what those changes will be (Walker 2012). Despite the increased attention toward resilience as a management framework and continued attention toward transformational change and transition management in the resilience approach, questions remain as to how to apply resilience in everyday management decisions (Carpenter et al. 2001, Folke et al. 2010). Natural systems are constantly changing, and the uncertainty of ecosystem responses to specific environmental stressors creates challenging situations for managers as they manage systems without complete knowledge of those stressors or their effects.
Climate change has come to the forefront as a potential largescale source of change in many ecosystems. Specifically, changes in temperature, precipitation, and frequency of extreme events will have significant effects on thresholds, which will affect ecosystem extent and composition, and there may be few options for interventional management (Harris et al. 2006, Williams and Jackson 2007, Lindenmayer et al. 2008). As a slow, persistent stressor, climate change will cause unidirectional changes within a system, and uncertainty remains as to how systems will respond. Gradual changes that allow ecosystems to slowly adapt can still be radically affected by extreme events that push systems across ecological thresholds. Variation in the type, scale, and rate of change will create difficulties in managing ecological systems.

Resilience management continues to be well positioned to theorize on how best to meet the challenges posed by climate change while maintaining the essential ecosystem functions for human and environmental well-being (Folke 2006). However, the dearth of knowledge regarding ecosystem transitions presents a true challenge, as many managers seek to maintain desired system attributes as close to their original form as possible (Millar et al. 2007). Climate change is also creating novel systems, which generate increasingly complex management scenarios (Hobbs et al. 2006), and many managers are waiting to see what will occur before acting. 
This leaves managers with little time to react and little control over the changes that will occur through time.

In most systems, dealing with climate change impacts will require prioritizing particular populations, species, and/or processes to preserve if the functions and character of the system are to be maintained. Therefore, we propose a practical approach, called guided transition, which can help guide the front-end decision-making of adaptive management in systems undergoing unidirectional change. Such an approach can be especially useful in systems where there is a strong desire to maintain specific functions for the sake of social, economic, or environmental goals. In guided transition, the traditional adaptive management process cycle is modified to include prioritization of specific functions to maintain as climate change affects the system. This stage comes after the particular threats climate change and other stressors pose to the system are identified, and it enables managers to prioritize elements to be conserved through the transition pathway in order to protect the desired functionality of the system (Fig. 1). Climate change will preclude maintaining all functions in perpetuity or across the entire system. Guided transition thus provides managers with an opportunity to detail their management priorities among the many possible management choices by identifying specific functions and outlining a proactive approach to devote resources towards their protection.

\section{RESILIENCE THEORY}

Ecological systems undergo stochastic events and their response indicates their level of resilience. Reduced resilience makes systems more fragile, which increases the possibility that a disturbance event could push a system into a different state (Scheffer et al. 2001). Scholars have put forth multiple terms and definitions to describe resilience (Carpenter et al. 2001), including equilibrium, ecosystems, and engineering resilience. Equilibrium resilience "concentrates on stability near an equilibrium steady-state, where resistance to disturbance and speed of return to the equilibrium are used to measure resilience" (Holling and Meffe 1996, Holling 2006). Ecosystem resilience "is the magnitude of disturbance that can be absorbed or accommodated before the system changes its structure by changing the variables and processes that control system behavior" (Holling 2006). Engineering resilience represents the time it takes a system to return to the same state after disturbance (Holling and Meffe 1996, Gunderson and Light 2006). Ultimately, resilience has come to embody a system that can persist after disturbance and harbor roughly the same functions and characteristics as the original system (Folke 2006).

Resilience scholars point out that resilience can have positive and negative connotations (Gunderson and Light 2006). Recovering after disturbance while maintaining functions clearly has positive consequences, but some systems can persist in a state that has negative consequences. In a more desirable state, resilience management seeks to promote action to maintain those systems; in a non-desirable state, management actions to reduce resilience are sometimes applied to change systems to more desirable states. However, unknown ecological thresholds complicate resilience management. Crossing a threshold could move the system into a new state, but identifying where those thresholds exist has proven elusive (Scheffer et al. 2009). Without the ability to pinpoint threshold boundaries, managers cannot predict when disturbance might move a system into a new state or into an increasing positive or negative state, which affects the desirability of the system to be maintained.

Fig. 1. Conceptual diagram of the adaptive management cycle using the guided transition approach. Within the adaptive management process cycle, guided transition helps direct the front end decision-making of problem assessment, design, and implementation (green circles) by directing the questions to focus on the functional changes of ecosystem transition through unidirectional climate change. This process also adds a step in prioritizing the functions to protect through the transition (dashed outline), which will help structure the design and implementation of adaptation plans.

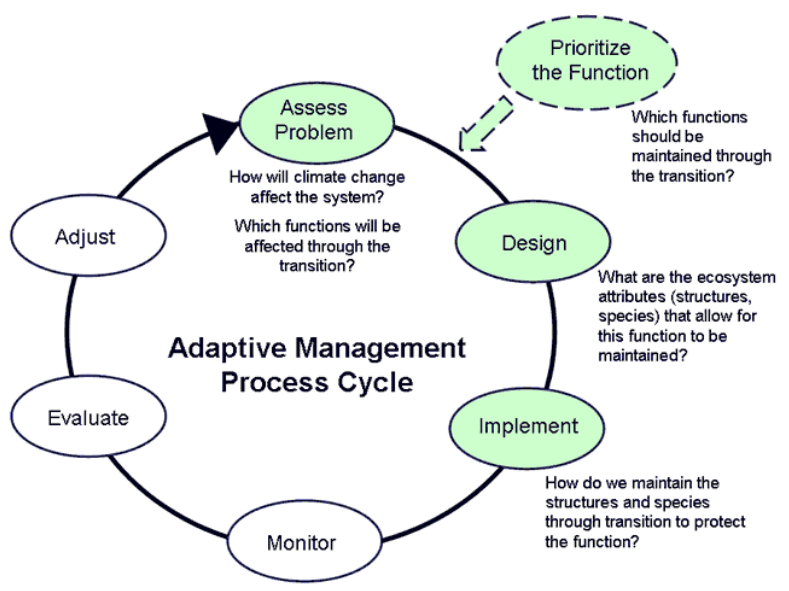

A system's resilience includes three properties-(1) the amount of change a system can undergo while maintaining structure and function, (2) the degree to which a system is capable of reorganization after a disturbance, and (3) the degree to which a particular system can learn and adapt (Carpenter et al. 2001), which draw attention to the linkage between ecological and human systems and the need for management. Resilience planning generally attempts to promote system resilience to either stave off state change due to disturbance or to recover function after disturbance.

Several approaches to managing for resilience have been put forth, namely adaptive management and resilience management. Resilience management inherently incorporates 
adaptive management but takes a broader approach to preventing or encouraging system change. Adaptive management entails integrating hypotheses and experimental trials into management rather than just relying on trial and error (Arvai et al. 2006). Over time, monitoring assesses whether those experiments have led to desired outcomes. If they have not, altered management actions are implemented and the process begins anew (Holling 1978, Walters 1986). This approach, supported by continual learning, holds the potential to engage system complexity in a proactive manner. However, this type of management requires a significant investment of time and money, particularly for long-term monitoring to evaluate whether interventions have produced desired outcomes. There is also little guidance in terms of how to approach adaptive management and guide the decisions to apply management interventions. Guided transition, as an approach to adaptive management, can assist in prioritizing specific functions for management action in order to efficiently use limited resources to produce desired outcomes. Climate change has renewed the call to implement adaptive management, particularly in the context of protected area management to help facilitate resilient systems (Baron et al. 2009). However, there currently is insufficient information to direct managers on how to accomplish this.

\section{UNDERSTANDING REGIME SHIFTS UNDER CLIMATE CHANGE}

Ecosystems are presumed to have a stable state that can be pushed across a threshold by one or a set of stressors to reach an alternative stable state (Groffman et al. 2006). A shift to an alternative stable state of an ecosystem occurs when a change in an environmental driver produces large and persistent responses in an ecosystem, thereby pushing the ecosystem across a threshold (Gunderson 2000). Some clear observations of threshold shifts include one well-known example of a reversible threshold shift, where nitrogen $(\mathrm{N})$ and phosphorus (P) non-point source deposition caused lakes to shift to eutrophic states, but lakes shifted back to the original regime when $\mathrm{N}$ and $\mathrm{P}$ deposition was reduced (Carpenter et al. 1998). In another well-known example of a large persistent shift, ponderosa pine forest shifts to piñon juniper woodland were observed in northern New Mexico due to a severe drought. The shift in vegetation cover persisted because the level of soil erosion and habitat fragmentation did not allow the system to return to its original state (Allen and Breshears 1998). Such examples show distinct state shifts where managers may want to reverse the shift after it has already occurred, but may be limited in their ability to shift back depending on the causal mechanism. As such, management of many systems has focused heavily on trying to understand the threshold levels of regime shifts in order to prevent the triggers that will cause them (Harris et al. 2006).

Such a pathway to management is difficult to determine when a variety of endogenous (soils, topography) and exogenous (climate, nutrient deposition) factors can cause regime changes. Vegetation changes on the lee side of mountains are examples of how slight changes in soil, sun angle, and wind pattern can affect species composition and community structure (Fairman et al. 2011). In some cases, the natural trajectory of vegetation systems may be to move toward alternative states unless a disturbance is maintained within the system, such as in the Burke Branch Barrens in southern Illinois, where prairie and open woodland are maintained through fire management (Anderson et al. 2000). In this case, the vegetation trajectory of the system is to move toward a closed, dense forest canopy but is prevented by fire frequency (Anderson et al. 2000). With the cessation of fire management, prairie species decline and the abundance of woodland species increase, which leads to the development of a closed forest canopy, an alternative state for the system. Such shifts point to the difficulty of maintaining terrestrial systems in their current state. Natural trajectories and endogenous/exogenous factors will continually shift communities toward alternative states. Therefore, managing systems to stay within their current boundaries, especially under persistent changes like climatic change, will become increasingly difficult.

There are a number of unknowns within climate induced transitions. It is unclear when a shift to an alternative state will have a negative effect on ecosystem function. Shifts that occur gradually through species composition shifts are often regarded as natural, expected changes in a landscape, and climate change effects may seem gradual and natural depending on the rate of change. It is also unclear whether a shift in ecosystem state for terrestrial systems under climate change is realistically preventable given that certain physiological and environmental thresholds will be inevitable in the future (Walker and Salt 2006). Although fire management has maintained the system within the Burke Branch Barrens, such persistent and large-scale levels of management may not be economically, socially, and technologically tenable in many other situations.

\section{WHICH SHIFTS MATTER?}

Many shifts in systems may not lead to negative consequences. In terrestrial systems, many small shifts that often occur have no large effect on the system. Ecosystems already harbor a large amount of natural resilience and adaptive capacity that allow them to change with shifting abiotic conditions (Landres 1999). Under smaller changes, natural genetic variation may allow for better adapted species to be selected, which would lead to small and potentially inconsequential changes in structure and function. Larger shifts may lead to a more extreme change in community composition, which may or may not have a large effect on structure and function depending on the type of shift experienced. For example, shifting water levels within a wetland yield different species compositions. As water levels increase, more high-water species appear due to the increase in water depth, and when the water levels 
decrease, the abundance of low-water species increase (Casanova and Brock 2000). Such shifts are considered neutral rather than negative for the communities because many functions are maintained within the wetland system.

There may be specific shifts that can have a profound effect on ecosystem form and function, and although not negative, they are not considered neutral. Some shifts in salinity may have negative effects on seedling recruitment in wetlands, and sea level rise may cause more permanent shifts in species composition (Conner et al. 1997), which could lead to communities with different functional capacities. Profound shifts are often difficult to predict, and more information on how community structure correlates to community function is required to identify why certain shifts have a greater influence than others on ecosystem change.

The study of novel ecosystems is one area that has developed to better understand how exogenous changes have affected community structure and ecosystem function. Novel ecosystems are defined as systems where the biota of a system respond to new environmental conditions (e.g., anthropogenic changes) through the development of a "novel community" composed of a new combination and relative importance of species (Hobbs et al. 2006, Williams and Jackson 2007). The novel community can often be dominated by a new set of species at the expense of native species (Abelleira Martínez et al. 2010), thereby changing community structure and the resulting functions. Future climates will likely create new environmental conditions with new species combinations (Williams and Jackson 2007). While smaller changes may result in hybrid systems that retain some original characteristics as well as novel elements, larger changes will result in novel systems comprised of different species, interactions, and functions that may not resemble the original systems (Hobbs et al. 2009).

Information gained from the study of invasive species as novel ecosystems may inform our understanding of how climate change will create novel ecosystems. Like climate change stressors, invasive species are often difficult to control, and they present a persistent stress to an ecosystem. However, evidence regarding the positive versus negative impacts of invasive species encroachment has been difficult to determine. The invasion paradox describes the co-occurrence of independent lines of support for both a negative and positive relationship between native biodiversity and the invasions of exotic species. Some positive associations are observed on the larger spatial scale, while there can be negative effects toward native diversity at the smaller scale (Fridley et al. 2007). The African tulip tree (Spathodea campanulata), an introduced species that forms novel forest types in Puerto Rico, has been observed to colonize land after deforestation, agricultural use, and land abandonment. Although these novel forests are less species rich than the native forests, $S$. campanulata restores forest structure and can provide suitable regeneration sites for native species in disturbed and post-abandonment lands (Abelleira Martínez et al. 2010), thereby leading to increased function with time. In contrast, surveys in Hawaii have found that native species within the exotic-dominated forests were likely survivors of past encroachment rather than new recolonizers and were slowly being outcompeted over time (Mascaro et al. 2008). Thus, novel systems created by invasives can sometimes replace lost functions and promote native species, while others can negatively affect native species and functions.

Of course climate change will also generate questions about what is native and what is invasive as communities shift with changes in the climate envelope. New species will come into communities and have a competitive advantage over once "native" species, and managers may have to be proactive about these shifts in order to practically guide the structure and function of these systems. A better understanding of how climate change stressors can change the structure of ecosystems can lead to a better understanding of the eventual changes in the overall ecosystem functions. The fluid adaptive ability already existent within ecosystems makes thresholds and trigger points difficult to detect and threshold shifts potentially very difficult to prevent (Scheffer et al. 2009). Considering the costs (effort, time, money) that may have to be employed in order to maintain systems, a rational method for guiding the adaptive management pathway for landscape transition will be required.

\section{OPPORTUNITIES TO MANAGE SHIFTS THROUGH GUIDED TRANSITION}

It is unknown to what extent changes in structure lead to a change in function. However, if goals are centered on maintaining desired functions within the system, this question will have to be answered in order to provide effective management. This will be especially true if the desired functions are important for societal well-being (e.g., water filtration, protection against storm surge) and if the functions are difficult to replicate or replace economically or technologically. Structure, function, and the environment all interact dynamically such that the structure-to-function relationship is dependent on the state of the environment. Therefore, as the environment changes with climate change, the relationship between structure and function will have to be adjusted in order to maintain function (Walker 1997).

Many systems will inevitably undergo a change in structure as climate change acts on the system, which will increase the difficulty of maintaining systems in their original state (Fig. 2, State 1) or restoring them from the alternative state (State 2) back to the original state (State 1). It is therefore important to consider the potential of managing the community structure of the alternative state (State 2) in a manner that maintains the desired functions of the system (Fig. 2b). Guided transition 
offers a specific approach that prioritizes the desired functional aspects of the system in deciding management interventions and may prove helpful for managers who apply adaptive management.

Fig. 2. Relationships between community structure and function can be affected by environmental changes, such as climate. In some systems, a shift to an alternative state can yield community structure changes that lead to a shift in ecosystem functions (a), but guided transition aims to guide the shift in community structure in such a way that some desired ecosystem functions can be maintained through the transition (b).

a.

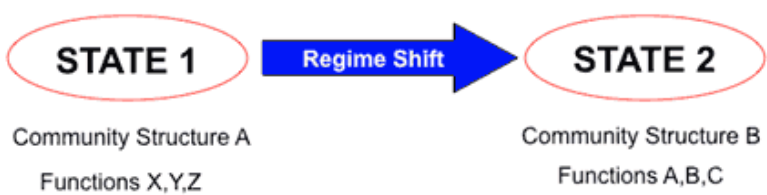

b.

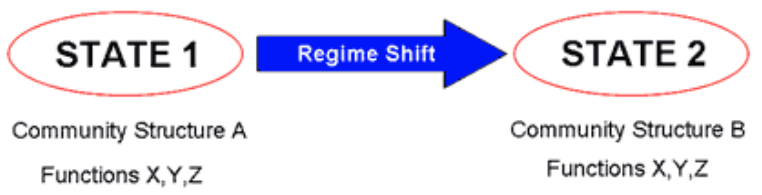

Guided transition provides managers with the ability to hone in on specific characteristics to manage across transitional shifts and focus on the functions that are important to the human-ecological system. Whereas resilience planning takes a broad view by considering resilience of the entire system, guided transition recognizes that climate change may negate the ability to maintain function across an entire system. Through guided transition, managers can pinpoint particular system functions to focus on and work to maintain them in particular areas. Thus, the system may change significantly, but guided transition will ensure that the function persists with the assistance of management intervention as the entire system undergoes change. This approach facilitates actions designed to address system components rather than the whole system, and potentially eases the management burden for practitioners. If the present community species cannot be maintained to provide the necessary structure for the function, then guided transition may require introducing alternative species replacements to maintain structure and function. This focus therefore reduces the range of potential management choices around a set of functions and allows for more efficient decision-making.

Guided transition, in a sense, is a manager-created alternative state (State 2) where species selection and community structures are strategically chosen through management intervention to form a community that can provide the desired ecosystem functions (Fig. 2b). Such an approach requires a good understanding of the ecological relationships within the system and the species and structures responsible for the desired functions. A suite of functions have been well studied and can be readily incorporated into the guided transition approach. Functions such as carbon sequestration, nutrient cycling, soil erosion control, microclimate control for insects and mammals, and habitat provision for many species are more generalizable functions that can be maintained through similar community structure. Therefore, if a management goal seeks to maintain carbon sequestration through the transition, a shift from one type of forest to another may be guided such that important forest structure is not lost. A change from a forest to a shrubland would yield a much larger change in community structure, and many of the desired functions (carbon sequestration, nutrient cycling, soil erosion control) could be maintained but reduced. Such a change in structure would yield a less desirable outcome than the forest if carbon sequestration was the desired function.

Some unique functions must be treated separately because they are more sensitive to the contributions of specific species and are more difficult to replace. Specific predator-prey relationships and pollination studies have demonstrated the need to maintain specific species within a system for the existence of particular functions. For example, in shade coffee systems, maintaining an open forest structure within the agroforestry system allows for extensive cross-habitat gene flow of a native tree, Miconia affinis, by specialized native pollinators (Jha and Dick 2010). This highlights how specific insect-plant relationships may be mediated by community structure and species selection, and that the understanding of the ecological mechanics of this particular function is required for management. Unlike the mechanics of more general functions like carbon sequestration, species-specific functions will be more difficult to maintain in the face of shifting ecosystems.

Such challenges in management are increasingly important in continually transitioning systems under unidirectional change parameters. The following case studies showcase such challenges and highlight how guided transition might enable them to maintain desired ecosystem function as climate change fundamentally alters the system.

\section{CASE STUDIES}

Examples of systems in various stages of transition exist within the current management literature. We show how the guided transition approach can be considered within the adaptive management framework. We present two case studies of systems that are facing changes and moving through the climate transition. The first case study, the Alligator River National Wildlife Refuge, represents a system that is already 
Fig. 3. Map of the Alligator River National Wildlife Refuge, where a guided transition type framework is being applied. Sea level rise is inundating much of the coastal habitat (a), and management to adapt to changing salinity and lost ecosystem structure has included planting saltwater-tolerant trees (b), building freshwater culverts to bring freshwater into salinized lands (c), and building oyster reefs to protect the shoreline (d). Photo credits: U.S. Fish and Wildlife Service and The Nature Conservancy
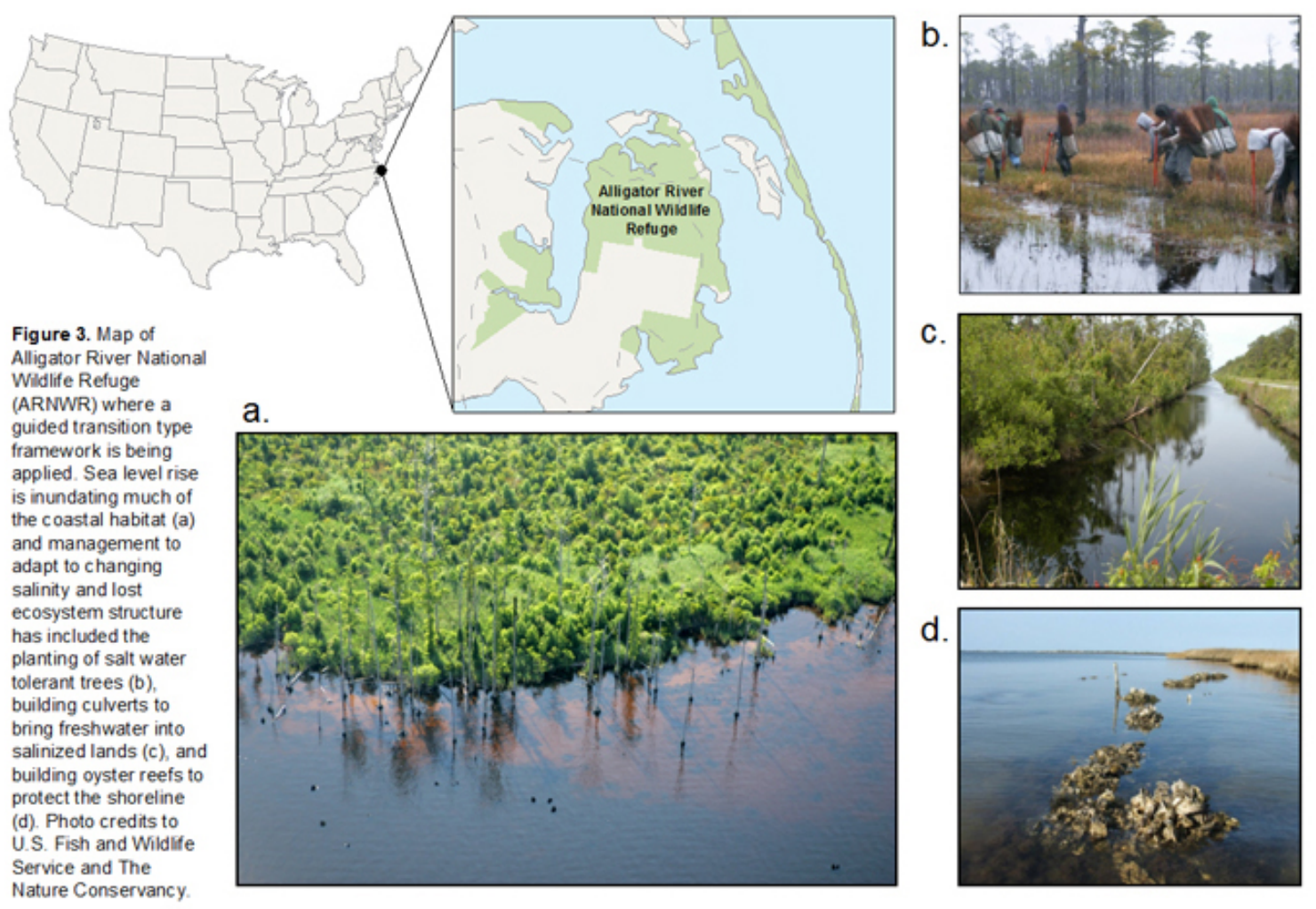

dealing with climate change through sea level rise, with practitioners using a guided transition approach to isolate and protect specific functions. In the second case study, climate change is altering the Boundary Waters Canoe Area Wilderness through changing temperature and humidity regimes. Managers have the opportunity to use the guided transition approach to maintain certain functions as the broader landscape undergoes dramatic changes.

\section{Alligator River National Wildlife Refuge}

In the Alligator River National Wildlife Refuge on the North Carolina coast, saltwater intrusion and sea level rise have rapidly changed the environmental conditions of the coastal forest habitat (Strickland 2011). The refuge covers 61,917 ha and was established in 1984 to provide protection for pocosins, unique, elevated shrubby wetlands (Lawler et al. 2008, U.S. Fish and Wildlife Service 2011). The pocosins are quite diverse and provide important habitat for many associated endangered species, including the Red-cockaded Woodpecker (Picoides borealis) and American alligator (Alligator mississippiensis), the reintroduced and endangered red wolf (Canis rufus), and one of the last remaining coastal populations of black bears (Ursus americanus) (U.S. Fish and Wildlife Service 2011). The refuge also provides a number of social public goods, including hunting and fishing habitat, wildlife photography, and environmental education (Fig. 3).

Much of the land area is extremely sensitive to sea level rise (Lawler et al. 2008), which has already changed salinity regimes in many wetlands and caused accelerated rates of soil erosion. This change will slowly turn forests into marshlands. One of the main desired functions of the refuge is the provision of habitat to support viable populations of the endangered and forest-dependent species. Therefore, management goals have been selected to maintain forest structure for as long as possible in order to give the land and its species time to adapt to sea level rise, increased salinity, and other climate change impacts (Strickland 2011). This process, which considers a specific, socially, and environmentally desired function in which to design an adaptive management plan, embodies the 
guided transition approach. Managers identified certain structural components of the system that had to be rehabilitated or replaced in order to maintain the habitat function, and then designed an appropriate management intervention to meet their goals.

In order to slow the rate of erosion and the large-scale loss of forests to marshland, a number of measures were taken (Fig. $3)$. New saltwater- and flood-tolerant trees were planted to replace saltwater-intolerant species and maintain the ecosystem structure of the forest. Culverts dug from the landward side provided an increased influx of freshwater to wetlands in order to restore the salinity gradient and protect saltwater-intolerant trees, and artificial oyster reefs were built along the shoreline to protect forests from further erosion due to storm surge (Strickland 2011). Many of these management actions were implemented to preserve the forest structure so that suitable habitat could be maintained for the species that are valued by the community. The ability to protect some freshwater trees and to replace some with saltwater-tolerant species aided in preserving key habitat structure in an inundated landscape. This example of a guided transition approach has helped managers adapt to unidirectional changes by adjusting species to maintain the forest structure and the desired function of habitat for endangered species. This function was used to guide and prioritize management decisions for the wildlife refuge.

\section{Boundary Waters Canoe Area Wilderness}

The Boundary Waters Canoe Area Wilderness (BWCAW) is a diverse forest system in northern Minnesota that is at risk from climate change due to changes in temperature and humidity regimes. The BWCAW encompasses more than 400,000 million hectares and is the most heavily visited wilderness area in the national forest system (Heinselman 1999). It adjoins the Quetico Provincial Park in Ontario, Canada, and together form a wilderness area of more than one million hectares. The area's protected status has contributed to expansive intact forest landscapes, the largest in the eastern United States, and has maintained habitat that has produced healthy populations of plant, insect, and animal species that are in decline elsewhere (Heinselman 1999).

Despite the BWCAW's relative health, climate change poses a significant threat to the area by shifting the system to a scrubbier, species-poor landscape (Frelich and Reich 2009). Historically, natural fire regimes in the BWCAW contributed to heterogeneous forests in diverse age classes of predominantly jack pine (Pinus banksiana) and aspen (Populus tremuloides) systems. Over the past century, however, fire suppression and forest management have dramatically reduced fire in the system (Frelich and Reich 1995), which has reduced the system's overall diversity. Changes in climate will also threaten and undermine the ecological character of the system by changing the climate parameters of the ecosystem (Frelich and Reich 2009). As Frelich and Reich (2009) state, "Whether transition to savanna or forest occurs, the vegetation of the BWCAW is likely to be in a state of flux for centuries while new species migrate in and develop the relationships among themselves and their environment that will define the future ecosystem."

Such a system is representative of many land management systems facing climate stressors. Climate flux is changing the structure of the forest system to scrub habitat, and novel ecosystems are expected to develop as new species migrate into the system and create new relationships between structure and function. A guided transition approach can assist managers in determining their adaptive management plan by identifying important functions within the system that should be preserved through the transition. For example, if carbon sequestration was a functional goal of the system, the implementation of prescribed fire may be necessary to maintain the landscape in a forest system rather than a scrubbier, carbon-poor landscape. Guided transition in this case may present a rational approach for moving forward in the adaptation management pathway by determining functions that are desired through the transition and finding management strategies that allow for those functions to persist through the shift.

Such examples show how the guided transition approach can provide a management pathway in the transition of ecosystems across climate change thresholds. In the Alligator River National Wildlife Refuge, the guided transition approach is already being implemented as saltwater-tolerant trees are planted to restore the community structure of the refuge for endangered wildlife species. Wildlife habitat is a socially and environmentally important function, as many tourists come to view and photograph the coastal wildlife. In the BWCAW case study, climate change is affecting forest composition and structure, which will lead to novel ecosystems in the future. This presents a system in which the guided transition approach can be implemented in order to ease the management burden of the changing landscape. Taking the step to consider and select the functions that should be maintained in the landscape can help prioritize management interventions for the wilderness area. Such examples highlight the great potential of using a guided transition approach in complex and difficultto-manage cases of climate-induced regime shifts by targeting adaptive management toward the increased resilience of specific desired functions.

\section{CONCLUSION}

Ecosystems will face a greater level of stress in the future due to changing environmental factors, and many ecosystems will be pushed across thresholds to alternative states with altered community structure and function. Although there is uncertainty regarding the effect of unidirectional changes, the ability to guide transitions by maintaining desired ecosystem 
functions is one useful way in which to ease the decision pathway of adaptive management.

A greater understanding of how community structure affects ecosystem function will have to be developed in order to aid in guided transitions. Identifying the relationships between desired functions and species-specific communities will be difficult yet necessary in order to manage community change toward structures with acceptable trajectories. Because some changes will be inevitable, the importance of prioritizing management for functions may be both an economically rational as well as an efficient way to consider transitioning ecosystems through threshold regime shifts. The ability of science to target and monitor important functions through time will be integral in protecting and effectively managing systems that are shifting with unidirectional climate change.

Responses to this article can be read online at: http://www.ecologyandsociety.org/issues/responses. php/5128

\section{Acknowledgments:}

We would like to thank Brian Walker and Jenny Langridge for their comments and advice on this manuscript and Christopher Clark for earlier discussions regarding the manuscript. We would like to thank Siobhan Duffy, U.S. Fish and Wildlife, and The Nature Conservancy for the graphics regarding the ARNWR. We would also like to thank the U.S. EPA, AAAS, CSIRO, and the W.K. Kellogg Biological Station at Michigan State University for their support.

\section{LITERATURE CITED}

Abelleira Martínez, O., M. Rodríguez, I. Rosario, N. Soto, A. López, and A. Lugo. 2010. Structure and species composition of novel forests dominated by an introduced species in northcentral Puerto Rico. New Forests 39:1-18.

Allen, C. D., and D. D. Breshears. 1998. Drought-induced shift of a forest-woodland ecotone: rapid landscape response to climate variation. Proceedings of the National Academy of Sciences 95:14839-14842. http://dx.doi.org/10.1073/ pnas.95.25.14839

Anderson, R. C., J. E. Schwegman, and M. R. Anderson. 2000. Micro-scale restoration: a 25-year history of a southern Illinois barrens. Restoration Ecology 8:296-306. http://dx.doi. org/10.1046/j.1526-100x.2000.80042.x

Arvai, J., G. Bridge, N. Dolsak, R. Franzese, T. Koontz, A. Luginbuhl, P. Robbins, K. Richards, K. S. Korfmacher, B. Sohngen, J. Tansey, and A. Thompson. 2006. Adaptive management of the global climate problem: bridging the gap between climate research and climate policy. Climatic Change 78:217-225. http://dx.doi.org/10.1007/s10584-006-9094-6

Baron, J. S., L. Gunderson, C. D. Allen, E. Fleishman, D. McKenzie, L. A. Meyerson, J. Oropeza, and N. Stephenson. 2009. Options for national parks and reserves for adapting to climate change. Environmental Management 44:1033-1042. http://dx.doi.org/10.1007/s00267-009-9296-6

Carpenter, S. R., N. F. Caraco, D. L. Correll, R. W. Howarth, A. N. Sharpley, and V. H. Smith. 1998. Nonpoint pollution of surface waters with phosphorous and nitrogen. Ecological Applications 8:559-568. http://dx.doi.org/10.1890/1051-0761 (1998)008[0559:NPOSWW]2.0.CO;2

Carpenter, S., B. Walker, J. M. Anderies, and N. Abel. 2001. From metaphor to measurement: resilience of what to what? Ecosystems 4:765-781. http://dx.doi.org/http://dx.doi.org/10.1007/ $\underline{\text { s10021-001-0045-9 }}$

Casanova, M. T., and M. A. Brock. 2000. How do depth, duration and frequency of flooding influence the establishment of wetland plant communities? Plant Ecology 147:237-250. http://dx.doi.org/http://dx.doi.org/10.1023/ A: 1009875226637

Conner, W. H., K. W. McLeod, and J. K. McCarron. 1997. Flooding and salinity effects on growth and survival of four common forested wetland species. Wetlands Ecology and Management 5:99-109. http://dx.doi.org/10.1023/A:1008251127131

Fairman, J. G., Jr., U. S. Nair, S. A. Christopher, and T. Mölg. 2011. Land use change impacts on regional climate over Kilimanjaro. Journal of Geophysical Research 116:D03110. http://dx.doi.org/10.1029/2010JD014712

Folke, C. 2006. Resilience: the emergence of a perspective for social-ecological systems analyses. Global Environmental Change 16:253-267. http://dx.doi.org/10.1016/j. gloenvcha.2006.04.002

Folke, C., S. R. Carpenter, B. Walker, M. Scheffer, T. Chapin, and J. Rockström. 2010. Resilience thinking: integrating resilience, adaptability and transformability. Ecology and Society 15 (4):20. http://www.ecologyandsociety.org/vol15/ iss $4 / \operatorname{art} 20 /$

Frelich, L. E., and P. B. Reich. 1995. Spatial patterns and succession in a Minnesota southern-boreal forest. Ecological Monographs 65:325-346. http://dx.doi.org/10.2307/2937063

Frelich, L. E., and P. B. Reich. 2009. Wilderness conservation in an era of global warming and invasive species: a case study from Minnesota's Boundary Waters Canoe Area Wilderness. Natural Areas Journal 29:385-393. http://dx.doi. org/10.3375/043.029.0405

Fridley, J. D., J. J. Stachowicz, S. Naeem, D. F. Sax, E. W. Seabloom, M. D. Smith, T. J. Stohlgren, D. Tilman, and B. 
Von Holle. 2007. The invasion paradox: reconciling pattern and process in species invasions. Ecology 88:3-17. http://dx. doi.org/10.1890/0012-9658(2007)88[3:TIPRPA]2.0.CO;2

Gallopín, G. C. 2006. Linkages between vulnerability, resilience, and adaptive capacity. Global Environmental Change 16:293-303. http://dx.doi.org/10.1016/j.

gloenvcha.2006.02.004

Groffman, P., J. Baron, T. Blett, A. Gold, I. Goodman, L. Gunderson, B. Levinson, M. Palmer, H. Paerl, G. Peterson, N. Poff, D. Rejeski, J. Reynolds, M. Turner, K. Weathers, and J. Wiens. 2006. Ecological thresholds: the key to successful environmental management or an important concept with no practical application? Ecosystems 9:1-13. http://dx.doi.org/ http://dx.doi.org/10.1007/s10021-003-0142-z

Gunderson, L. H. 2000. Ecological resilience-in theory and application. Annual Review of Ecology and Systematics 31:425-439. http://dx.doi.org/10.1146/annurev.ecolsys.31.1.425

Gunderson, L., and S. Light. 2006. Adaptive management and adaptive governance in the everglades ecosystem. Policy Sciences 39:323-334. http://dx.doi.org/10.1007/s11077-006-9027-2

Harris, J. A., R. J. Hobbs, E. Higgs, and J. Aronson. 2006. Ecological restoration and global climate change. Restoration Ecology 14:170-176. http://dx.doi.org/10.1111/ j.1526-100X.2006.00136.X

Heinselman, M. 1999. The Boundary Waters Wilderness Ecosystem. University of Minnesota Press, Minneapolis, Minnesota, USA.

Hobbs, R. J., S. Arico, J. Aronson, J.S. Baron, P. Bridgewater, V. A. Cramer, P. R. Epstein, J. J. Ewel, C. A. Klink, A. E. Lugo, D. Norton, D. Ojima, D. M. Richardson, E. W. Sanderson, F. Valladares, M. Vilà, R. Zamora, and M. Zobel. 2006. Novel ecosystems: theoretical and management aspects of the new ecological world order. Global Ecology and Biogeography 15:1-7. http://dx.doi.org/10.1111/ j.1466-822X.2006.00212.X

Hobbs, R. J., E. Higgs, and J. A. Harris. 2009. Novel ecosystems: implications for conservation and restoration. Trends in Ecology \& Evolution 24:599-605. http://dx.doi. org/10.1016/j.tree.2009.05.012

Holling, C. S., editor. 1978. Adaptive environmental assessment and management. Wiley, London, UK.

Holling, C. S. 2006. Engineering resilience versus ecological resilience. Pages 51-66 in L. H. Gunderson, C. R. Allen, and C. S. Holling, editors. Foundations of ecological resilience. Island Press, Washington. D.C., USA.

Holling, C. S., and G. K. Meffe. 1996. Command and control and the pathology of natural resource management. Conservation Biology 10:328-337.
Jha, S., and C. W. Dick. 2010. Native bees mediate longdistance pollen dispersal in a shade coffee landscape mosaic. Proceedings of the National Academy of Sciences 107:13760 13764. http://dx.doi.org/10.1073/pnas.1002490107

Landres, P. B. 1999. Overview of the use of natural variability concepts in managing ecological systems. Ecological Applications 9:1179-1188.

Lawler, J. J., T. H. Tear, C. Pyke, M. R. Shaw, P. Gonzalez, P. Kareiva, L. Hansen, L. Hannah, K. Klausmeyer, A. Aldous, C. Bienz, and S. Pearsall. 2008. Resource management in a changing and uncertain climate. Frontiers in Ecology and the Environment 8:35-43. http://dx.doi.org/10.1890/070146

Lindenmayer, D. B., J. Fischer, A. Felton, M. Crane, D. Michael, C. Macgregor, R. Montague-Drake, A. Manning, and R. J. Hobbs. 2008. Novel ecosystems resulting from landscape transformation create dilemmas for modern conservation practice. Conservation Letters 1:129-135. http://dx.doi. org/10.1111/j.1755-263X.2008.00021.X

Mascaro, J., K. K. Becklund, R. F. Hughes, and S. A. Schnitzer. 2008. Limited native plant regeneration in novel, exoticdominated forests on Hawai'i. Forest Ecology and Management 256:593-606. http://dx.doi.org/10.1016/j. foreco.2008.04.053

Millar, C. I., N. L. Stephenson, and S. L. Stephens. 2007. Climate change and forests of the future: managing in the face of uncertainty. Ecological Applications 17:2145-2151. http:// dx.doi.org/10.1890/06-1715.1

Scheffer, M., S. Carpenter, J. A. Foley, C. Folke, and B. Walker. 2001. Catastrophic shifts in ecosystems. Nature 413:591-596. http://dx.doi.org/10.1038/35098000

Scheffer, M., J. Bascompte, W. A. Brock, V. Brovkin, S. R. Carpenter, V. Dakos, H. Held, E. H. van Nes, M. Rietkerk, and G. Sugihara. 2009. Early-warning signals for critical transitions. Nature 4610:53-59. http://dx.doi.org/10.1038/ $\underline{\text { nature } 08227}$

Strickland, J. 2011. North Carolina: working with nature to prepare for the change. U.S. Fish and Wildlife Service. [online] URL: http://www.fws.gov/news/blog/index.cfm/2011/5/5/ North-Carolina-Working-with-Nature-to-Prepare-for-the-Change

U.S. Fish and Wildlife Service. 2011. Alligator River National Wildlife Refuge. [online] URL: http://www.fws.gov/ alligatorriver/

Walker, B. H. 1997. Functional types in non-equilibrium ecosystems. Pages 91-103 in T. H. Smith, H. H. Shugart, and F. I. Woodward, editors. Plant functional types; their relevance to ecosystem properties and global change. IGBHP Book Series, Vol. 1. Cambridge University Press, Cambridge, UK. 
Walker, B. 2012. Building Australia's resilience. Australia 21, Canberra, Australia.

Walker, B., and D. Salt. 2006. Resilience thinking: sustaining ecosystems and people in a changing world. Island Press, Washington, D.C., USA.

Walters, C. J. 1986. Adaptive management of renewable resources. MacMillan, New York, USA.

Williams, J. W., and S. T. Jackson. 2007. Novel climates, noanalog communities, and ecological surprises. Frontiers in Ecology and the Environment 5:475-482. http://dx.doi. org/10.1890/070037 